\title{
The budget and cycle of Earth's natural chlorine
}

\author{
T.E. Graedela and W.C. Keene ${ }^{\mathrm{b}}$ \\ a Bell Laboratories, Lucent Technologies, Murray Hill, NJ 07974, USA \\ ${ }^{b}$ University of Virginia, Charlottesville, VA 22903, USA
}

\begin{abstract}
Earth's chlorine, retained when the planet was formed from the Solar nebula, is contained largely in three reservoirs: the mantle $(99.6 \%)$, the crust $(0.3 \%)$, and the oceans $(0.1 \%)$. Only oceanic chlorine is readily mobile, cycling among the lower and middle atmosphere, the pedosphere, freshwaters, and the cryosphere. Inter-reservoir chlorine fluxes are estimated for all transitions of interest; by far the most important on a mass basis is the injection of seasalt from the oceans to the atmosphere, and its return to the planetary surface by wet and dry deposition.
\end{abstract}

\section{INTRODUCTION}

The use of chlorine and chlorine-containing compounds by industry and in water purification is currently the focus of considerable debate and possible regulatory action by the U.S., Canadian, and European governments. Proposed regulatory strategies have substantial implications for many segments of the world economy including water purification, the manufacture of paper, solvents, plastics, pharmaceuticals and other chemicals, and industries that rely on these products. Large uncertainties in our understanding of the natural biogeochemistry of chlorine have traditionally confounded critical assessment of the potential environmental impact of anthropogenic influences, since natural reservoirs and processes are important and often dominant components of the terrestrial, aquatic, marine, and tropospheric chlorine budgets. Some aspects of Earth's natural chlorine cycle have been reviewed [1-5]. However, an integrated approach incorporating major components of the natural chlorine cycle and recent reports should provide valuable perspective for scientists and policy makers. In this paper we review available information concerning the major natural reservoirs and associated chemical processes relevant to the global chlorine cycle.

\section{THE ORIGIN OF EARTH'S CHLORINE}

Of the 92 natural elements, chlorine is eighteenth in order of abundance. It is an element commonly encountered by humanity, ubiquitously present in table salt and in seawater. Like all the natural elements, chlorine is a gift from the stars. As astrophysicists have reconstructed the picture, the Big Bang generated large amounts of hydrogen, some of which condensed to form stars. The high pressures and temperatures in the cores of early (and present) stars are sufficient to permit nuclear reactions, such as the formation of helium from hydrogen, a reaction that provides, in the case of our Sun, the light and heat on which civilization depend. As stars age, their cores become increasingly hotter and more compact, and additional nuclear reactions become possible. Details are contained in the astrophysical literature [e.g. 6,7]; suffice it to say that among the elements produced in good yield is chlorine.

Stars have finite lifetimes of perhaps 5-15 billion years, after which many undergo the violent supernova stage in which interior heat and related radiation pressure exceed the gravitational forces holding them together. The stellar constituents, chlorine included, are thus widely dispersed throughout space. It was such material that slowly condensed some five billion years ago to form our Solar System and our planet Earth.

Chlorine in the early Earth is thought to have been largely contained in the interior. Because $\mathrm{HCl}$ is highly volatile, however, it was readily outgassed as a component of volcanic eruptions. In the atmosphere the $\mathrm{HCl}$ was taken up in precipitation and transferred to the ground, just as it is today. Chlorine does not tend to remain where it falls, because inorganic chlorine compounds are highly soluble, so one does not find those compounds as major constituents of igneous or metamorphic rocks. Similarly, chlorine is highly 


\section{Stratosphere}
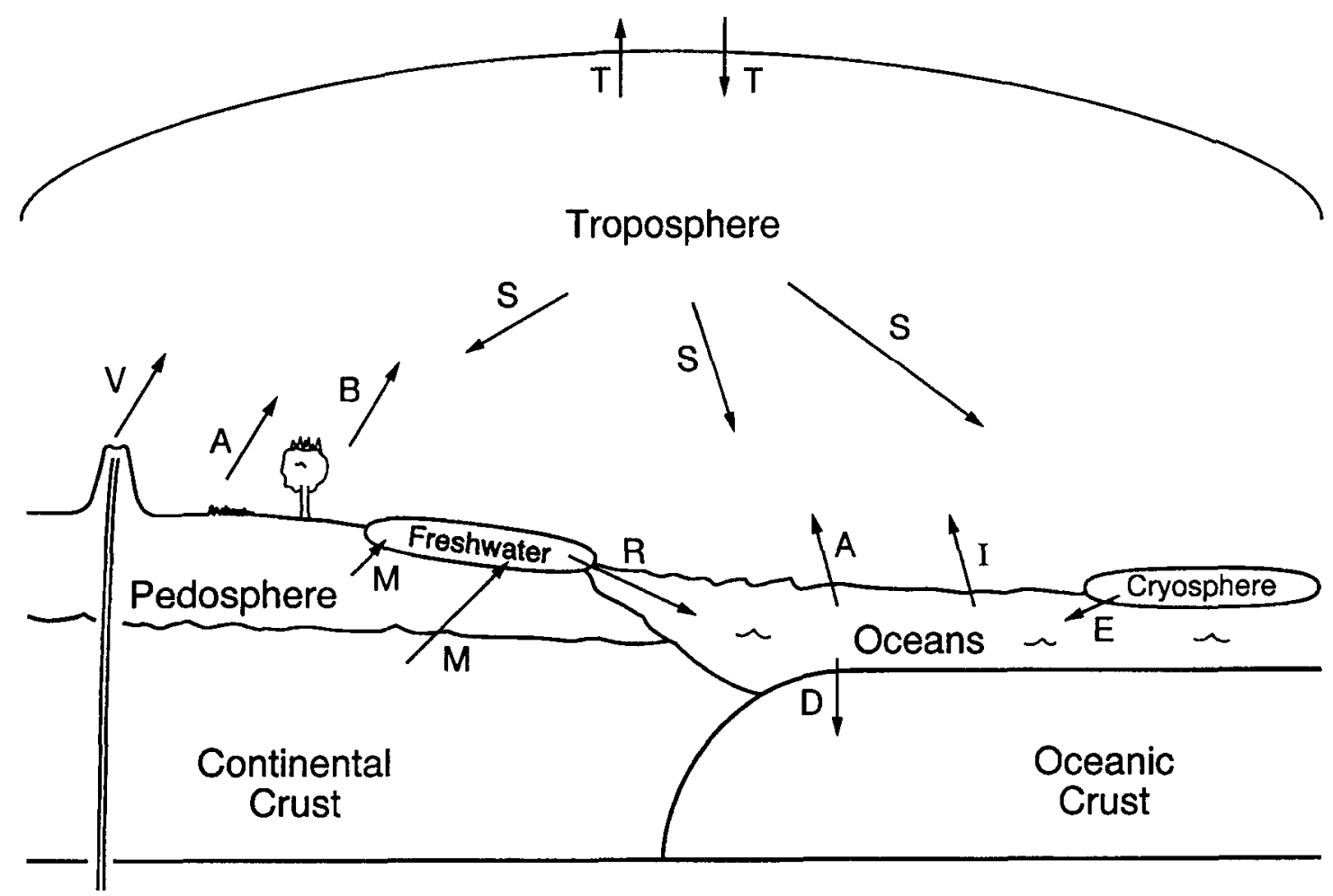

Mantle

Fig. 1 The planetary chlorine reservoirs. The natural processes transferring chlorine among the reservoirs are: A, algae and fungi; B, biomass burning; D, diagenesis, E, elution; I, sea spray injection; $M$, mineral dissolution; R, runoff; $\mathrm{S}$, surface deposition; $\mathrm{T}$, turbulent mixing, and $\mathrm{V}$, volcanism.

mobile in soils [8]. The result is that the bulk of the chlorine that is emitted to the atmosphere and falls upon the land is ultimately transferred to the oceans [9]. If an efficient transport route to the oceans is unavailable, the chlorine will accumulate on land in sedimentary salt beds [10]. These beds, found the world over, are the immediate source of virtually all the chlorine in commercial use.

\section{CHLORINE RESERVOIRS}

Earth's chlorine resides in several major reservoirs (Fig. 1): rock (the mantle and crust), soil (the pedosphere), freshwater (groundwater, lakes, and rivers), saltwater (the oceans), ice caps and glaciers (the cryosphere), the lower atmosphere (the troposphere), and the middle atmosphere (the stratosphere). The total chlorine content of these reservoirs differs enormously. To facilitate discussion we express elemental concentrations with the IUPAC-approved prefixes for large numbers: yottagrams $\left(\mathrm{Yg}=10^{24} \mathrm{~g}\right)$, zettagrams $(\mathrm{Zg}=$ $\left.10^{21} \mathrm{~g}\right)$, exagrams $\left(\mathrm{Eg}=10^{18} \mathrm{~g}\right)$, petagrams $\left(\mathrm{Pg}=10^{15} \mathrm{~g}\right)$, teragrams $\left(\mathrm{Tg}=10^{12} \mathrm{~g}\right)$, and gigagrams $(\mathrm{Gg}=$ $\left.10^{9} \mathrm{~g}\right)$. Rates of flow are expressed in the units of teragrams per year.

\section{The mantle, crust and pedosphere}

The amount of chlorine in Earth's mantle can be derived, at least approximately, by assuming it to be equal to the proportion of chlorine in the Solar nebula. This quantity is established by analysis of meteorites, and is given by Cameron [11] as $190 \mathrm{Cl}$ atoms per $10000 \mathrm{Si}$ atoms. Given that silicon is 15 weight percent of the material that accreted to form Earth [12], and the mass of Earth is $6000 \mathrm{Yg}$, the chlorine content of Earth's interior is approximately $22 \mathrm{Yg} \mathrm{Cl}$. 
The amount of chlorine in the crust (i.e., chlorine theoretically accessible to humanity) can also be readily approximated. We begin with the information that the chlorine abundance of the crust is 0.19 weight percentage [12]. The crust averages about $20 \mathrm{~km}$ in thickness, and has a mean density of order $2.9 \mathrm{~g} / \mathrm{cm}^{3}$. The chlorine content of the crust is thus approximately $60 \mathrm{Zg} \mathrm{Cl}$. As stated above, this chlorine is not at all equally distributed, but is concentrated in sedimentary salt beds.

The high variability of chlorine concentrations in the soil make it difficult to derive an accurate overall total, but an order of magnitude estimate can be produced as follows. The mean soil depth over the continental areas not covered by ice is about $2 \mathrm{~m}$ [13] and the mean soil density about $1.0 \mathrm{~g} / \mathrm{mL}$. Arimoto (Private communication, 1995) has estimated the average soil concentration of chlorine to be $100 \mathrm{ppmw}$. Given the ice-free areas of the continents, these figures produce a total pedospheric reservoir content of about $24 \mathrm{Pg} \mathrm{Cl}$.

\section{The oceans}

Oceans are the primary reservoir for chlorine in Earth's hydrosphere. With a water volume of about $1.36 \times 10^{8} \mathrm{~km}^{3}$ [14] and an average $\mathrm{Cl}$ concentration of $19.354 \mathrm{~g} / \mathrm{kg}$ [15], the ocean contains approximately $26 \mathrm{Zg} \mathrm{Cl}$. Available evidence suggests that the chlorine content of seawater has remained relatively constant over the past 600 million years, although small fluctuations are expected based on the presence or absence of significant evaporite pans [14].

\section{Surface waters}

Water in lakes and rivers comprises some $1 \times 10^{5} \mathrm{~km}^{3}$, and the water contained as soil moisture is roughly equivalent in amount. Though these are substantial quantities, they are tiny when related to the global hydrological budget. The average concentration of nonanthropogenic, dissolved $\mathrm{Cl}$ in rivers is about $5.8 \mathrm{mg} /$ $\mathrm{L}$ [16]. Thus, the reservoir content is of order $580 \mathrm{Tg} \mathrm{Cl}$.

\section{Groundwater}

The groundwater in aquifers and soils comprises about $8 \%$ of Earth's water [17], and has a typical chlorine concentration of $40 \mathrm{mg} / \mathrm{L} \mathrm{[18].} \mathrm{The} \mathrm{content} \mathrm{of} \mathrm{chlorine} \mathrm{in} \mathrm{the} \mathrm{groundwater} \mathrm{reservoir} \mathrm{is} \mathrm{thus} 320 \mathrm{Pg} \mathrm{Cl}$.

\section{The cryosphere}

When rain or snow falls on polar or continental ice, most of the ionic content is eluted into surrounding waters as the firn consolidates and freezes [19]. Sulfate and nitrate are expecially prone to elution, while chlorine is retained somewhat more efficiently; its average residual concentration is $5 \times 10^{-7} \mathrm{M} \mathrm{Cl} / \mathrm{L}$. Given the volume of ice on the planet of $29 \mathrm{~km}^{3}$ [14], this gives a cryospheric chlorine content of approximately $0.5 \mathrm{Gg} \mathrm{Cl}$.

\section{The troposphere}

Most volatile chlorine in the atmosphere exists as $\mathrm{HCl}$ and $\mathrm{CH}_{3} \mathrm{Cl}$ [4]. Near the surface in remote oceanic regions, concentrations of 100-300 pptv $\mathrm{HCl}$ are commonly measured. Over remote land areas, the concentrations appear to be at least that low and perhaps lower, though the data are quite variable and intercomparison of techniques is urgently needed. In or near urban areas, the minimum concentration is again at or near $100 \mathrm{pptv}$, but the high concentrations range up to about $3000 \mathrm{pptv}$. The data suggest the possibility that coastal urban areas have higher ambient $\mathrm{HCl}$ concentrations than do continental urban areas, but the range is such that local sources often must dominate any natural backgrounds. Overall, the average boundary layer concentration of natural gaseous $\mathrm{HCl}$ is about $200 \mathrm{pptv}$, giving a tropospheric reservoir concentration of about $0.2 \mathrm{Tg} \mathrm{Cl}$.

The dependence of $\mathrm{HCl}$ with altitude reflects both its sources and the rate at which it is removed from the atmosphere by chemical reactions or physical processes. Within a few hundred meters of the ground, the limited measurements show small to moderate decrease in $\mathrm{HCl}$ abundance with height. Above the 
boundary layer, the concentrations fall off sharply to $\leq 100 \mathrm{pptv}$. Given the volume of the free troposphere, this implies an $\mathrm{HCl}$ content for the free troposphere of about $0.4 \mathrm{Tg} \mathrm{Cl}$.

Methyl chloride is an abundant natural reactive chlorine-containing gas in the troposphere. Its concentrations are relatively constant in time and latitude at about $620 \mathrm{pptv}$, a level that produces a reservoir content for the troposphere of about $3.7 \mathrm{Tg} \mathrm{Cl}$.

The chlorine content of the atmosphere due to seasalt aerosol varies widely as a function of wind speed and wave action. Typical concentrations measured from ships are average about $100 \mathrm{~nm} / \mathrm{m}^{3}$ [4]. When measured from aircraft at several thousand feet, these concentrations drop by perhaps an order of magnitude; obviously most of the seasalt aerosol is injected only into low altitudes and redeposits rather quickly. If we assume the concentration given above to apply within a boundary layer of thickness $1 \mathrm{~km}$, the resulting chlorine burden contained in transitory seasalt particles in the lower troposphere is between 1 and 1.5 $\mathrm{Tg} \mathrm{Cl}$.

\section{The stratosphere}

Although the total chlorine content of the stratosphere is about $3 \mathrm{ppbv}$ at present, most of this is anthropogenic material. The natural level due to methyl chloride is about 0.7 p.p.b. (M. McFarland, Private communication, 1993). Given the total mass of the stratosphere, this average concentration gives a reservoir content of about $0.4 \mathrm{Tg} \mathrm{Cl}$.

\section{INTER-RESERVOIR TRANSFERS}

\section{Mantle to troposphere}

Volcanic eruptions are prolific sources of $\mathrm{HCl}$. The extremely sporadic numbers and magnitudes of volcanic eruptions ensure that the source rate of volcanic $\mathrm{HCl}$ will be highly variable. Nonetheless, a rough range of 0.4-11 Tg Cl/year has been suggested by Symonds et al. [20]. Because $\mathrm{HCl}$ is highly soluble, and volcanic eruptions generate substantial clouds and rain, most of the chlorine is quickly deposited at the surface. Very little remains in the troposphere for long periods, and virtually none reaches the stratosphere [21].

Some of the volcanic chlorine may be directly extracted from chlorine in the mantle, but the bulk of it is thought to be due to seawater entering magma chambers, being chemically processed, and being emitted along with other gases and particles during explosive eruptions. We arbitrarily assign one-third of the volcanic chlorine emissions (say an average of $2 \mathrm{Tg} \mathrm{Cl} /$ year) to extraction from the mantle reservoir, and the remainder to ocean-troposphere transfer.

Although many other chlorine-containing gases are emitted from volcanoes [22], their formation at magma chamber conditions is not favored [20], and their fluxes can be ignored.

\section{Ocean to troposphere}

\section{Seasalt aerosol and volatile inorganic $\mathrm{Cl}$}

Breaking waves on the ocean surface produce seasalt aerosols in the marine boundary layer (MBL) [23]. This natural process is the major source for atmospheric chlorine; estimated production rates range from about 6-18 Pg Cl/year [24]. Most of this material is deposited to the ocean surface via wet and dry deposition but multi-phase chemical processes in the MBL convert a portion of the particulate chlorine to volatile products $[25,26]$. This process is the major global source of gaseous chlorine in the troposphere.

Until recently, it was widely assumed that the only significant mechanism by which seasalt is dechlorinated involves acidification of the aerosol by $\mathrm{H}_{2} \mathrm{SO}_{4}$ and $\mathrm{HNO}_{3}$, with subsequent volatilization of $\mathrm{HCl}$ [27]. Graedel \& Keene [4] estimate a flux of $\mathrm{HCl}$ via this pathway of about $50 \mathrm{Tg} \mathrm{Cl} /$ year based on the combined effect of both anthropogenic and natural reactants. Assuming that anthropogenic emissions have increased the combined flux of $\mathrm{SO}_{2}$ and oxidized $\mathrm{N}$ into the MBL by a factor of about two, we estimate that the production of $\mathrm{HCl}$ from direct reactions involving naturally derived acids and seasalt aerosol would be about half the estimate for the present epoch, or about $25 \mathrm{Tg} \mathrm{Cl} /$ year.

Several lines of evidence from recent investigations suggest that, in addition to $\mathrm{HCl}$, highly reactive $\mathrm{Cl}$ 
gases such as $\mathrm{Cl}_{2}, \mathrm{HOCl}, \mathrm{ClNO}_{2}$, and $\mathrm{BrCl}$ may also volatilize from seasalt aerosol [4,28]. Photolysis of these gases during the daytime produces atomic $\mathrm{Cl}$ with potential implications for the atmospheric lifetimes of alkanes, methyl halides, and dimethylsulfide [29]. A very preliminary estimate [4] suggests production rates for photolyzable $\mathrm{Cl}$-atom precursors ranging from $<100-800 \mathrm{Tg} \mathrm{Cl} /$ year and an average concentration in the MBL of about $75 \mathrm{pptv}(0.1 \mathrm{Tg} \mathrm{Cl})$.

Organic Cl gases

A large number of chlorinated organic compounds are produced naturally and emitted from the ocean surface and from terrestrial ecosystems (e.g., 30). $\mathrm{CH}_{3} \mathrm{Cl}$ is the principal chlorocarbon emitted to the atmosphere from these sources. Based on inferred transfer coefficients and concurrent measurements in surface ocean waters and in air at the same location, Tait et al. [31] estimate that about $2 \mathrm{Tg} \mathrm{Cl} / \mathrm{year} \mathrm{CH}_{3} \mathrm{Cl}$ is emitted from the open ocean to the atmosphere. Based on measured concentrations of $\mathrm{CH}_{3} \mathrm{Cl}$ and its reaction rate constant with $\mathrm{OH}$, the global source strength for $\mathrm{CH}_{3} \mathrm{Cl}$ is estimated to be about $3.4-5 \mathrm{Tg} \mathrm{Cl} /$ year $[4,32]$. Subtracting the biomass burning flux of about $0.9 \mathrm{Tg} \mathrm{Cl} /$ year and the estimated oceanic flux of $2.0 \mathrm{Tg} \mathrm{Cl} /$ year yields a negligible to modest residual, which presumably reflects the combined contributions of natural terrestrial and industrial sources, neither of which appear to be significant in terms of the global chlorine budget.

\title{
Pedosphere to troposphere
}

\begin{abstract}
Mineral aerosol
Wind storms during dry seasons sporadically inject large amounts of desert soil dust into the middle troposphere where it is transported thousands of kilometers by the prevailing winds before removal by wet and dry deposition [33,34]. Mineral aerosol contains significant amounts of chlorine [35] and is the major natural reservoir of particulate chloride in the continental boundary layer over much of Earth and probably in the free troposphere on a global scale. Approximately $73 \mathrm{Tg} /$ year of mineral aluminum is derosited from the atmosphere to the world's oceans [36]. Assuming a similar flux of mineral Al to continents (probably an underestimate) and a mass ratio of $\mathrm{Cl}$ to $\mathrm{Al}$ in desert dust of 0.10 [37], about $15 \mathrm{Tg} / \mathrm{year}$ of crustal $\mathrm{Cl}$ must be emitted to the atmosphere to balance the estimated deposition flux.
\end{abstract}

\section{Biomass burning}

All biomass contains chlorine and 70-85\% of the chlorine in biomass is emitted to the atmosphere during combustion $[32,38]$. Of the emitted fraction, probably greater than $90 \%$ is released as inorganic $\mathrm{Cl}, 2 \%$ to $3 \%$ as $\mathrm{CH}_{3} \mathrm{Cl}$, and minor fractions as other chlorinated compounds.

Andreae [39] estimates that biomass burning emits about $0.9 \mathrm{Tg} \mathrm{Cl} /$ year of $\mathrm{CH}_{3} \mathrm{Cl}$ to the atmosphere. Assuming that this corresponds to $3 \%$ of the total emission flux of $\mathrm{Cl}$ from burning [32], we estimate a total flux of about $30 \mathrm{Tg} \mathrm{Cl} /$ year. If $\mathrm{HCl}$ and particulate $\mathrm{Cl}$ comprise $90 \%$ of the total emission flux, then approximately $27 \mathrm{Tg} \mathrm{Cl} /$ year of inorganic $\mathrm{Cl}$ are currently emitted to the atmosphere from biomass burning. Because only about $10 \%$ of present-day biomass burning is natural [40, J. Levine, Private communication, 1996], we estimate that about $3 \mathrm{Tg} \mathrm{Cl}$ /year of inorganic $\mathrm{Cl}$ and about $0.1 \mathrm{Tg} \mathrm{Cl} /$ year of $\mathrm{CH}_{3} \mathrm{Cl}$ are emitted to the atmosphere from natural flame combustion.

\section{Troposphere to surface}

Deposition to the surface is the principal sink for $\mathrm{HCl}$ and for particulate $\mathrm{Cl}$ associated with seasalt and mineral aerosol. The wet deposition flux of tropospheric chlorine to the pedosphere and cryosphere is computed by taking the corresponding annual average rainfall of $110000 \mathrm{~km}^{3} /$ year [41] and the average $\mathrm{Cl}^{-}$concentration in remote continental precipitation of $5 \mathrm{~mm}$ [4], giving about $20 \mathrm{Tg} \mathrm{Cl} /$ year. Assuming a similar flux from dry deposition yields a total flux from the troposphere to Earth's land and ice covered surface of about $40 \mathrm{Tg} \mathrm{Cl} /$ year. This amount must be divided among the fluxes to the pedosphere and the cryosphere. Although a definitive determination would take into account the precipitation characteristics of the different regions, we can get order-of-magnitude estimates by dividing the total deposition flux on the basis of the land and cryosphere surface fractions. This gives $34 \mathrm{Tg} \mathrm{Cl} /$ year from troposphere to pedosphere and $6 \mathrm{Tg} \mathrm{Cl} /$ year from troposphere to cryosphere. 
The flux of chlorine from the troposphere to the oceans is very large relative to all other fluxes in the global chlorine budget except the complementary flux of injected seasalt, whose minimal estimated amount is some $6000 \mathrm{Tg} \mathrm{Cl} /$ year [24]. With some minor contributions from magma intrusion and organic $\mathrm{Cl}$ gases (see above), the total may be something like $6006 \mathrm{Tg} \mathrm{Cl} /$ year. Since there appears to be no increase in the labile chlorine content of the troposphere, and given that the mantle and pedosphere are minor tropospheric chlorine sources and the cryosphere a minor tropospheric sink, we set the troposphere to ocean flux to $5990 \mathrm{Tg} \mathrm{Cl} /$ year to balance the tropospheric chlorine budget. Of that amount, about $80 \%$ is due to gravitational settling of seasalt aerosol and about $20 \%$ to the deposition of chlorine in precipitation [24].

\section{Troposphere to stratosphere}

Chlorinated gases emitted to the troposphere that have a sufficiently long lifetime will be transported into the stratosphere. Prior to industrialization, $\mathrm{CH}_{3} \mathrm{Cl}$ emitted from the ocean, terrestrial ecosystems, and natural biomass burning was the principal source of stratospheric chlorine. The flux has been estimated by Graedel \& Crutzen [17] as $0.03 \mathrm{Tg} \mathrm{Cl} /$ year.

\section{Stratosphere to troposphere}

Under the assumption that the natural chlorine content of the stratosphere is stable, the chlorine flux from the stratosphere into the troposphere must be equivalent to that from the troposphere to the stratosphere, or $0.03 \mathrm{Tg} \mathrm{Cl} /$ year.

\section{Rivers to oceans}

The average annual flux of river water from continents to the oceans is about $38 \times 10^{3} \mathrm{~km}^{3}$ and that of groundwater to the oceans about $2.2 \times 10^{3} \mathrm{~km}^{3} /$ year [14]. At a typical riverine chlorine concentration of $7 \mathrm{mg} \mathrm{Cl} / \mathrm{L}$ [42], we calculate that about $220 \mathrm{Tg} \mathrm{Cl} /$ year of naturally produced $\mathrm{Cl}$ is transported by rivers to the ocean each year.

\section{Crust to freshwater}

Riverine chlorine is not solely atmospheric: perhaps $80 \%$ of it results from the weathering of Cl-containing minerals in sandstone and shales, and from thermal and mineral springs in volcanic areas $[8,14]$. Thus, some $175 \mathrm{Tg} \mathrm{Cl} /$ year of the total flux from rivers to oceans is attributable to weathering of the crust.

\section{Pedosphere to freshwater}

$\mathrm{Cl}^{-}$deposited on land does not easily absorb onto surfaces nor are significant amounts incorporated into minerals that form in soils [8]. Although significant cycling within watersheds has been observed, and although some chlorine precipitates in dry areas as evaporites, most atmospheric $\mathrm{Cl}$ deposited by wet and dry processes onto continents efficiently passes through watersheds to surface waters [43]. This flux is roughly equivalent for the two processes; we estimate a total of about $34 \mathrm{Tg} \mathrm{Cl}$ /year. In addition, there is an unknown amount of loss of chlorine from evaporite beds into freshwater. To balance the freshwater reservoir, which appears not to be gaining or losing chlorine, we estimate the evaporite to freshwater flux at $11 \mathrm{Tg} \mathrm{Cl} /$ year.

\section{Oceans to crust}

The flux of oceanic $\mathrm{Cl}$ to the sedimentary reservoir via diagenesis (e.g., 10) is estimated to be about $17 \mathrm{Tg} \mathrm{Cl} /$

Table 1 The natural chlorine contents of Earth's reservoirs

\begin{tabular}{lll}
\hline Reservoir & Chlorine content & Form \\
\hline Mantle & $22 \mathrm{Yg}$ & Mineral \\
Crust & $60 \mathrm{Zg}$ & Mineral \\
Oceans & $26 \mathrm{Zg}$ & Ionic \\
Pedosphere & $24 \mathrm{Pg}$ & Mineral \\
Freshwater & $320 \mathrm{Pg}$ & Ionic \\
Cryosphere & $0.5 \mathrm{Gg}$ & Ionic \\
Troposphere & $4.3 \mathrm{Tg}$ & Gaseous \\
Troposphere & $1.0 \mathrm{Tg}$ & Aerosol \\
Stratosphere & $0.4 \mathrm{Tg}$ & Gaseous \\
\hline
\end{tabular}


year; losses of oceanic $\mathrm{Cl}$ from precipitation in present-day evaporite pans are considered insignificant [14]. The apparent imbalance between inputs and outputs is consistent with the hypothesis that concentrations of oceanic $\mathrm{Cl}$ are slowly increasing due to the current lack of large evaporite pans on Earth's surface [14].

\section{THE NATURAL CHLORINE BUDGET AND CYCLE}

For the convenience of the reader, we collect the estimated chlorine contents of the eight reservoirs in Table 1 , and the inter-reservoir transfer fluxes in Table 2. Using this information, we then put together an overall budget and cycle for natural chlorine, as pictured in Fig. 2. The difference in the reservoir contents of chlorine is particularly striking. The mantle holds the most chlorine by far, but it is almost completely inaccessible, the only transfer being small fluxes (in a relative sense) from volcanic eruptions. The chlorine content of the crust is lower than that of the mantle by a factor of about 20. Crustal chlorine also is involved in very little cycling, the only outflow being due to weathering. The pedosphere, with much less chlorine, also loses very minor amounts to weathering. The hydrosphere has four orders of magnitude less chlorine than the crust, but that chlorine is supremely accessible, and is the reservoir from which all significant chlorine cycling begins. The atmospheric reservoir is another five orders of magnitude smaller in chlorine content, and the cryosphere holds a tiny amount of chlorine relative to all the other reservoirs. Hence, even though the reservoir contents given here are relatively crude estimates, the relative differences in content are so great that the order of importance of the reservoirs is well established.

The relative importance of the fluxes among the reservoirs is also in little doubt. The production of seasalt aerosol by turbulence at the ocean surface and its direct deposition via wet and dry processes back to the ocean surface are by far the largest fluxes. Also of interest is the sequence of seasalt dechlorination, incorporation of volatile and particulate chlorine into precipitation, wet and dry deposition over land, and runoff that transfers chlorine from the pedosphere to freshwater and finally back to the ocean.

By our assessment, four of the chlorine reservoirs are in balance if only natural fluxes are considered: the stratosphere, the troposphere, the cryosphere, and freshwaters. Four are unbalanced: the mantle (due to volcanic emissions), the crust (due to the dissolution of mineral constituents), the pedosphere (due to the dissolution of evaporites and subsequent transfer of ionic chlorine and eroded soil to the oceans), and the oceans (due to the combination of soil inflow and diagenetic flow to the crust). We have constructed the global budget to be in balance, and indeed no chlorine can escape the planet. The separate components of the budget are not static, however, but are in constant evolution. Stochastic events such as volcanic eruptions and periods of enhanced sedimentation can result in depletion from or accretion to any of the reservoirs on a variety of time scales from short to long.

As a caution to the reader, we conclude by emphasizing the preliminary nature of the estimates made in this paper. Although there is little question of the rank ordering of the chlorine reservoirs or of the fluxes among them, the individual quantitative estimates have moderate to high uncertainty. Achieving a reliable quantitative budget for Earth's chlorine will involve extensive observations and the integration of spatially- and temporally-varying chlorine concentration information, especially so far as the crust and 


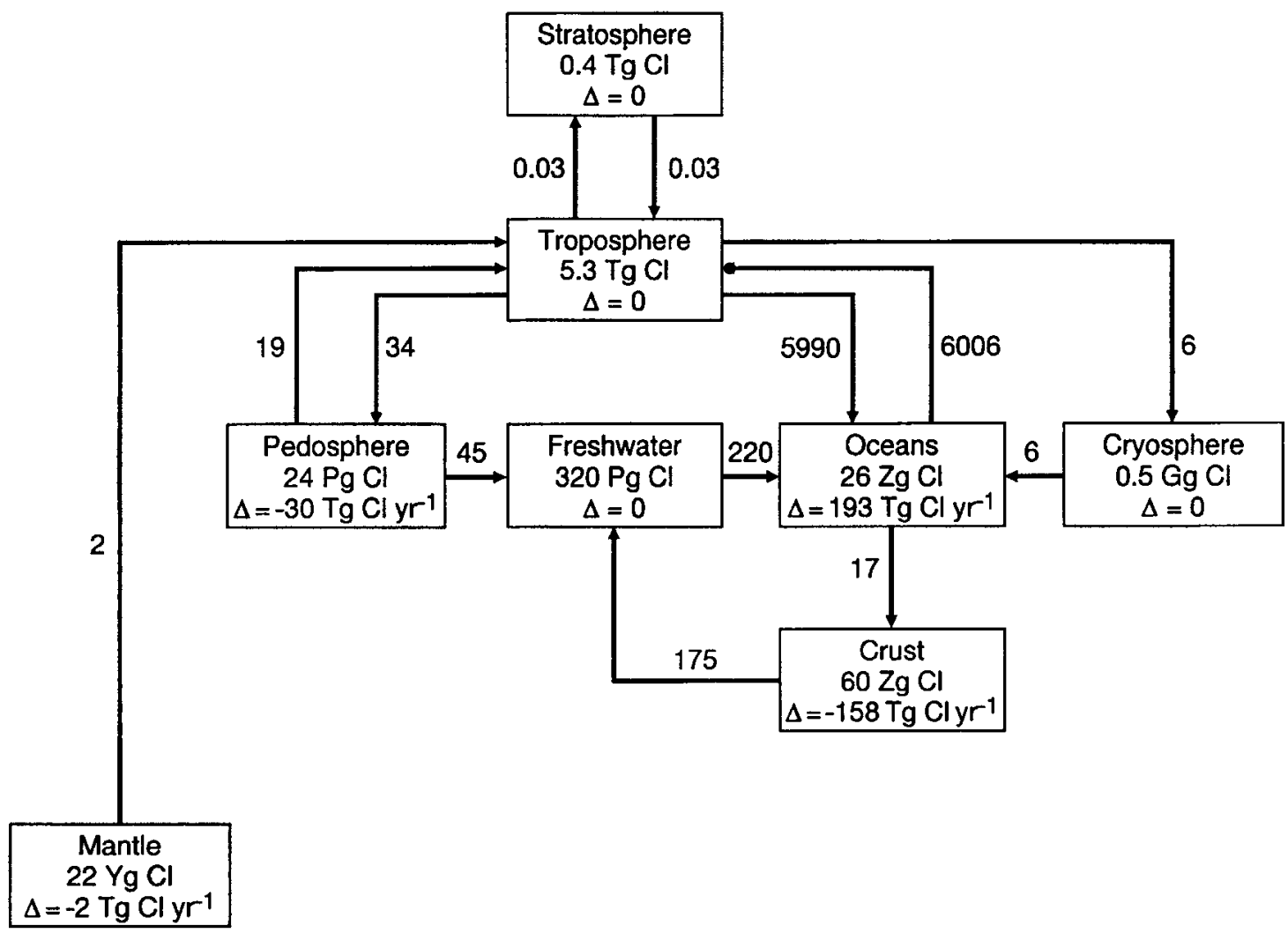

Fig 2 The chlorine budget and cycle for the five planetary reservoirs. The fluxes and reservoir content changes are in units of $\mathrm{Tg} / \mathrm{year}$. The processes responsible for the transfers are given in the caption to Fig. 1 .

pedosphere are concerned. As with all of science, while much is understood, much remains to be done.

\section{ACKNOWLEDGEMENTS}

For helpful comments on drafts of this paper and for furnishing information prior to publication we thank W.R. Emanuael, J.N. Galloway, D.B. Harper, M.A.K. Khalil, A. McCulloch, A.A.P. Pszenny, and T. Smith.

\section{REFERENCES}

1 R.J. Cicerone. Rev. Geophys. Space Phys., 19, 123-139 (1981).

2 P. Fabian. In The Handbook of Environmental Chemistry, vol. 4, Part A (O. Hutzinger, ed.), pp. 23-51, Springer-Verlag, Berlin (1986).

3 J.P. Friend. In Scientific Assessment of Stratospheric Ozone: 1989, Vol. II, Appendix: AFEAS Rep. No. 20, Global Ozone Res., Monit. Proj., World Meteorol. Org., Geneva (1989).

4 T.E. Graedel, W.C. Keene. Global Biogeochem. Cycles, 9, 47-77 (1995).

5 H.B. Singh. In Composition, Chemistry and Climate of the Atmosphere, (H. B. Singh, ed.), pp. 216-250, VNR Publishers, New York (1995).

6 V. Trimble. Rev. Modern Phys., 47, 877-967 (1975).

7 M. Arnould, K. Takahashi. In Origin and Evolution of the Elements (N. Prantzos, E. Vangioni-Flam, M. Casse, eds.), pp. 395-411, Cambridge Univ. Press, Cambridge, U.K. (1993).

8 R.F. Stallard, J. M. Edmond. J. Geophys. Res., 86, 9844-9858 (1981).

9 F. MacIntyre. Scient. Amer., 223 (5), 104-115 (1970).

10 R. Siever. Scient. Amer., 230 (6), 72-79 (1974).

11 A.G.W. Cameron. In Origin and Distribution of the Elements (L.H. Ahrens, ed.), pp. 125-143, Pergamon Press, Oxford, U.K. (1968). 
12 F. Press, R. Siever, Earth, 2nd ed., W.H. Freeman \& Co., San Francisco (1978).

13 R.S. Webb, C.E. Rosenzweig, E.R. Levine.A Gridded Data Set of Soil Particle Size Properties, NASA Technical Memorandum 4286, 34 pp. (1991).

14 E.K. Berner, R.A. Berner. The Global Water Cycle: Geochemistry and Environment, 397 pp., Prentice Hall, Englewood Cliffs, New Jersey (1987).

15 T.R.S. Wilson. In Chemical Oceanography, vol. 1, 2nd ed. (J. P. Riley, G. Skirrow, eds.), pp. 365-413, Academic, Orlando, Fla. (1975).

16 M. Meybeck. In Material Fluxes on the Surface of the Earth, National Research Council, pp. 61-73, National Academy Press, Washington D.C. (1994).

17 T.E. Graedel, P.J. Crutzen. Atmospheric Change: An Earth System Perspective, 446 pp., W.H. Freeman, Co., New York (1993).

18 A. Freeze, J. Cherry. Groundwater, Prentice Hall, Inc., Englewood Cliffs, NJ (1979).

19 T.D. Davies, C.E. Vincent, P. Brimblecombe. Nature, 300, 161-163 (1982).

20 R.B. Symonds, W.I. Rose, M.H. Reed. Nature, 334, 415-418 (1988).

21 A. Tabazadeh, R.P. Turco. Science, 260, 1082-1086 (1993).

22 G.W. Gribble. J. Natural Prod., 55, 1353-1395 (1992).

23 D.C. Blanchard, A.H. Woodcock. Ann. New York Acad. Sci, 338, 330-347 (1980).

24 D.J. Erickson III, R.A. Duce. J. Geophys. Res., 93, 14079-14088 (1988).

25 C.S. Martens, J.J. Wesolowski, R.C. Harriss, R. Kaifer. J. Geophys. Res., 78, 8778-8792 (1973).

26 W.C. Keene, A.A.P. Pszenny, D.J. Jacob, R.A. Duce, J.N. Galloway, J.J. Schultz-Tokos, H. Sievering, J.F. Boatman. Glob. Biogeochem. Cycles, 4, 407-430 (1990).

27 P. Brimblecombe, S. L. Clegg. J. Atmos. Chem., 7, 1-18 (1988).

28 R. Vogt, P.J. Crutzen, R. Sander, EOS, Trans. Amer. Geophys Union, 76 (46), 108-109 (1995).

29 W.C. Keene, D.J. Jacob, S.-M. Fan. Atmos. Environ., 30 (6), i-iii (1996).

30 A. Grimvall, E. W. B. de Leer (eds.), Naturally-Produced Organohalogens, Kluwer Academic Publ., Dordrecht, The Netherlands (1995).

31 V.K. Tait, R.M. Moore, R. Tokarczyk. J. Geophys. Res., 99, 7821-7833 (1994).

32 M.O. Andreae, E. Atlas, G.W. Harris, G. Helas, A. Kock, R. Koppmann, W. Maenhaut, S. Mano, W.H. Pollock, J. Rudolph, D. Scharffe, G. Schebeske, M. Welling. J. Geophys. Res., 101, in press (1996).

33 J.M. Prospero. In The Oceanic Lithosphere, vol. 7, The Sea, (C. Emiliani, ed.), pp. 801-874, John Wiley, New York (1981).

34 R. Swap, M. Garstang, S. Greco, R. Talbot, P. Kallberg. Tellus, 44B, 133-149 (1992).

35 R.W. Talbot, R.C. Harriss, E.V. Browell, G.L. Gregory, D.I. Sebacher, S.M. Beck. J. Geophys. Res., 91, 5173$5182(1986)$.

36 R.A. Duce, P.S. Liss, J.T. Merrill, E.L. Atlas, P. Buat-Menard, B.B. Hicks, J.M. Miller, J.M. Prospero, R. Arimoto, T.M. Church, W. Ellis, J.N. Galloway, L. Hansen, T.D. Jickells, A.H. Knap, K.H. Reinhardt, B. Schneider, A. Soudine, J.J. Tokos, S. Tsunogai, R. Wollast, M. Zhou. Glob. Biogeochem. Cycles, 5, 193-259 (1991).

37 J.S. Adepetu, O.I. Asubiojo, F.Y. Iskander, T.L. Bauer. J. Radioanal. Nuclear Chem., 121, 141-147 (1988).

38 L.M. McKenzie, E.E. Ward, W.M. Hao. Proc. Chapman Conf. on Biomass Burning and Global Change (J. Levine, ed.), in press (1996).

39 M.O. Andreae. In Biogeochemistry of Global Change: The Radiatively Active Trace Gases (R.S., Oremland,ed.), pp. 113-150, Chapman \& Hall, New York (1993).

40 J.S. Levine, Ed., Global Biomass Burning, MIT Press, Cambridge, MA (1991).

41 M.I. L'vovich. Trans. Amer. Geophys. Union, 54 (1), 28-42 (1973).

42 R.A. Smith, R.B. Alexander, M.G. Wohlman. Science, 235, 1607-1615 (1987).

43 J.H. Feth. Chloride in natural continental water - A review, U.S.G.S. Water Supply Paper No. 2176, 30 pp. (1981). 